\title{
PRICE-BASED UNIT COMMITMENT
}

\begin{abstract}
Alexander Mészáros

There are two major objectives in establishing an electricity market: ensuring a secure operation and facilitating an economical operation. Security is the most important aspect of the power system operation be it a regulated operation or a restructured power market. In a restructured power system, security could be ensured by utilizing the diverse services available to the market. The economical operation facilitated by the electricity market is believed to help reduce the cost of electricity utilization, which is a primary motive for restructuring and a way to enhance the security of a power system through its economics. To accomplish these objectives, proper market tools must be devised and efficient market strategies must be employed by participants based on power system requirements.
\end{abstract}

\section{INTRODUCTION}

In the regulated power industry, unit commitment (UC) refers to optimizing generation resources to satisfy load demand at least cost. Since the related objective would be to minimize operational cost, unit commitment is commonly referred to as cost-based unit commitment. If maintaining security is emphasized in the UC solution, the new UC is referred to as security-constrained unit commitment (SCUC). Three elements are included in the SCUC paradigm: supplying load, maximizing security, and minimizing cost. Satisfying the load is a hard constraint and an obligation for SCUC. Maximizing security is often satisfied by maintaining sufficient spinning reserve at less congested regions that could easily be accessed by loads. Cost minimization is realized by committing less expensive units while satisfying the corresponding constraints and dispatching the committed units economically.

In comparison, the UC used by individual generating companies (GENCOs) refers to optimizing generation resources in order to maximize the GENCO's profit. This UC has a different objective than that of SCUC and is referred to as price-based unit commitment (PBUC) to emphasize the importance of the price signal. In PBUC, satisfying load is no longer an obligation and the objective would be to maximize profit, and security would be unbundled from energy and priced as an ancillary service.

In comparing SCUC with PBUC, it is wrong to assume that maximizing the profit is essentially the same as minimizing the cost. Profit is defined as the revenue minus cost. That is, profit not only depends on cost but on revenue as well. If the incremental revenue is larger than the incremental cost, we may generate more energy for attaining more profit. On the contrary, if the incremental revenue is smaller than the incremental cost, it may be less attractive to sell energy. In an extreme case, if the objective in the new paradigm is to minimize the cost, a GENCO might not opt to generate because it would have no incentive to serve a load at zero cost.

\section{PBUC FORMULATION}

The objective of PBUC is to maximize the profit (i.e., revenue minus cost) subject to all prevailing constraints. For unit $i$ at time $t$, the profit is given as

$$
F(i, t)=\left\{\begin{array}{l}
\rho_{g m}(t)\left[P(i, t)-P_{0}(i, t)\right]+\rho_{r m}(t) R(i, t)+\rho_{n m}(t) N(i, t) \\
-C_{i}(P(i, t)+R(i, t)+N(i, t))-S(i, t)+f_{i}\left(P_{0}(i, t)\right)
\end{array}\right\} I(i, t)+
$$




$$
+\left\{\begin{array}{l}
\rho_{n m}(t) N(i, t)-\rho_{g m}(t) B(i, t) \\
-C_{i}(N(i, t))+f_{i}\left(P_{0}(i, t)\right)
\end{array}\right\}(1-I(i, t))
$$

$F(i, t) \quad$ Profit of unit $i$ at time $t$,

$P(i, t) \quad$ Generation of unit $i$ at time $t$,

$P_{0}(i, t) \quad$ Bilateral contract of unit $i$ at time $t$,

$R(i, t) \quad$ Spinning reserve of unit $i$ at time $t$,

$N(i, t) \quad$ Non-spinning reserve of unit $i$ at time $t$,

$S(i, t) \quad$ Start-up cost of unit $i$ at time $t$,

$f_{i}\left(P_{0}(i, t)\right) \quad$ Profit from bilateral contract of unit $i$ at time $t$,

$B(i, t) \quad$ Power purchase of unit $i$ at time $t$,

$I(i, t) \quad$ Commitment state of unit $i$ at time $t$,

$C_{i}($.$) \quad Cost function of unit i, C_{i}(x)=a(i)+b(i) x+c(i) x^{2}$,

$\rho_{g m}(t) \quad$ Forecasted market price for energy at time $t$ for the system,

$\rho_{n m}(t) \quad$ Forecasted market price for non-spinning reserve at time $t$ for the system,

$\rho_{r m}(t) \quad$ Forecasted market price for spinning reserve at time $t$ for the system.

The first part of the formula (1) represents the profit when the unit is ON. Profit is defined as the revenue from the sales of energy and ancillary services minus production costs. The profit from bilateral contracts would also be included, though it is assumed to be constant. The second part of the formula (1) represents the profit when the unit is OFF. Here, profit represents revenue from the non-spinning reserve sales minus production costs and the cost of any energy purchases. Similarly, profit from bilateral contracts would also be included.

In the scheduling horizon, the profit for all scheduled units is given as

$$
F=\sum_{i} \sum_{t} F(i, t)
$$

The PBUC problem is formulated as maximize $\sum_{i} \sum_{t} F(i, t)$ subject to system and unit constraints.

Lagrangian relaxation is used to solve PBUC. The basic idea is to relax coupling constraints (i.e., coupling units, time periods, or both) into the objective function by using Lagrangian multipliers. The relaxed problem is then decomposed into subproblems for each unit. The dynamic programming process is used to search the optimal commitment for each unit. Lagrangian multipliers are then updated based on violations of coupling constraints.

\section{ECONOMIC DISPATCH}

Once the unit commitment status is determined, an economic dispatch problem is formulated and solved to ensure feasibility of the original unit commitment solution. The economic dispatch problem at time $t$ is given as

$$
\text { minimize } \sum_{i}-F(i, t)
$$

subject to energy, reserve, and unit generation limits. Here unlike (1) the value of $I(i, t)$ is already determined and is no longer a variable. Therefore, quadratic or linear programming can be applied to solve this problem.

\section{Economic Dispatch for Non-spinning Reserve $(N)$}

Since $I(i, t)$ is given in the unit commitment section, the formulation is as follows: minimize 


$$
\sum_{i}\left\{-\rho_{n m}(t) N(i, t)+C_{i}\left(P_{g \min }(i)+N(i, t)\right)\right\}(i, t)+\sum_{i}\left\{-\rho_{n m}(t) N(i, t)+C_{i}(N(i, t))\right\}(1-I(i, t))
$$

subject to

$$
\begin{array}{ll}
0 \leq N(i, t) \leq G_{\max }(i, t)-P_{g \min }(i) & \text { (Unit is ON) } \\
0 \leq N(i, t) \leq G 0_{\text {max }}(i, t) & \text { (Unit is OFF) } \\
N^{\min }(t) \leq N(i, t) \leq N^{\max }(t) &
\end{array}
$$

$G_{\max }(i, t)$ is the maximum capability of unit $i$ at time $t$ when unit $i$ is ON. In some ramping cases, $G_{\max }(i, t)$ may be different from the maximum physical capacity of the unit. $\mathrm{G}_{\max }(i, t)$ is the maximum capability of unit $i$ at time $t$ when unit $i$ is OFF, which is the quick start capability of the unit, if available, and otherwise it is zero. The solution method is given as follows.

1. Determine $N_{\min }(i, t)$ and $N_{\max }(i, t)$, and using $\rho_{\text {nm }}(t)$, find $N(i, t)$ subject to $N_{\min }(i, t)$ and $N_{\max }(i, t)$.

$$
\begin{array}{ll}
N(i, t)=\frac{\rho_{n m}(t)-b(i)}{2 c(i)}-P_{g \text { min }}(i) & (\text { Unit is ON) } \\
N(i, t)=\frac{\rho_{n m}(t)-b(i)}{2 c(i)} & \text { (Unit is OFF) } \\
N_{\text {min }}(i, t) \leq N(i, t) \leq N_{\text {max }}(i, t) &
\end{array}
$$

2. If $N^{\min }(t) \leq \sum_{i} N(i, t) \leq N^{\max }(t)$, end.

3. If $\sum_{i} N(i, t)>N^{\max }(t)$, let $\sum_{i} N(i, t)=N^{\max }(t)$ and compute $N(i, t)$ again.

4. If $\sum_{i} N(i, t)<N^{\min }(t)$, let $\sum_{i} N(i, t)=N^{\min }(t)$ and compute $N(i, t)$ again.

The size of decomposed problem is on-third that of the original problem. Note that classical economic dispatch methods, such as lamba iteration method, first-order gradient method and second-order gradient method can be used to compute $N$. Also, quadratic or linear programming may be used in this approach.

\section{Economic Dispatch for Spinning Reserve $(R)$}

In the following formulation, $I(i, t)$ is given in the unit commitment section:

minimize

$$
\sum_{i}\left\{-\rho_{r m}(t) R(i, t)+C_{i}\left(P_{g \text { min }}(i)+N(i, t)+R(i, t)\right)\right\}(i, t)
$$

subject to (for all ON units)

$$
\begin{aligned}
& 0 \leq R(i, t) \leq G_{\max }(i, t)-P_{g \min }(i)-N(i, t) \\
& R^{\min }(t) \leq R(i, t) \leq R^{\max }(t)
\end{aligned}
$$

The solution is given as follows.

1. Determine $R_{\min }(i, t)$ and $R_{\max }(i, t)$, and using $\rho_{r m}(t)$, find $R(i, t)$ subject to $R_{\min }(i, t)$ and $R_{\max }(i, t)$. 


$$
\begin{aligned}
& R(i, t)=\frac{\rho_{r m}(t)-b(i)}{2 c(i)}-P_{g \text { min }}(i)-N(i, t) \\
& R_{\text {min }}(i, t) \leq R(i, t) \leq R_{\text {max }}(i, t)
\end{aligned}
$$

2. If $R^{\min }(t) \leq \sum_{i} R(i, t) \leq R^{\max }(t)$, end.

3. If $\sum_{i} R(i, t)>R^{\max }(t)$, let $\sum_{i} R(i, t)=R^{\max }(t)$ and compute $R(i, t)$ again.

4. If $\sum_{i} R(i, t)<R^{\min }(t)$, let $\sum_{i} R(i, t)=R^{\min }(t)$ and compute $R(i, t)$ again.

\section{CONCLUSIONS}

The formulation and the solution methodology for the PBUC problem in a restructured market structure can be used by GENCOs in some restructured markets where GENCOs are responsible for unit commitment. The solution methodology allows GENCOs to commit and schedule their units for selling power, purchasing power, selling spinning and non-spinning reserves in order to maximize their profits.

This paper was written under solving science project ŠP VaV 2003 SP $260280 B 02$.

\section{REFERENCES}

[1] Kolcun, M. - Griger, V. - Mühlbacher, J.: Electric Power System Operation Control. Košice: Mercury Smékal, 2003. 298 p. ISBN 80-89061-86-9

[2] Shahidehpour, M. - Yamin, H. - Li, Z.: Market Operations in Electric Power Systems: Forecasting, Scheduling, and Risk Management. New York: John Wiley \& Sons, Inc., 2002. 531p. ISBN 0-471$44337-9$

[3] Klíma, J.: Optimalizace v energetických soustavách. Praha: Academia, 1985. 304 p.

[4] Šimunek, P. - Mészáros, A.: Moderné trendy ekonomiky elektroenergetiky. Košice: Mercury-Smékal, 2003. 97 p. ISBN 80-89061-74-5

[5] Dvorský E. - Hejtmánková, P.: Optimalizace nasazování a provozu kogeneračních jednotek. In: The effective Use of Physical Theories of Conversion of Energy 2003. Plzeň: ZČU, 2003. pp. 77 - 82. ISBN 80-7082-959-1

[6] Martínek, Z. - Novák, P. - Nechanický, M.: Effect Regulation and Automatization of System on Reliability Level of Electric Supply. In: Distributed Power Generation Systems 2004. Plzeň: ZČU, 2004. pp. 90 - 98. ISBN 80-7043-283-7

[7] Tesařová, M.: Zajištění kvality elektrické energie. In: Use of Technical Measurements in Solving Environmental Problems 2000. Plzeň: ZČU, 2000. pp. 118-122. ISBN 80-7082-662-2

\section{Author address:}

Ing. Alexander Mészáros, PhD.

Department of Electric Power Engineering

Faculty of Electrical Engineering and Informatics, Technical University of Košice

Mäsiarska 74

04120 KOŠICE, Slovak Republic

E-mail: Alexander.Meszaros@tuke.sk

Tel.: +421/55/602 3555

Fax: +421/55/602 3552 